\title{
Clinical impact of nasal budesonide treatment on COPD patients with coexistent rhinitis
}

This article was published in the following Dove Press journal:

International Journal of COPD

\author{
Cecilia Calabrese' \\ Adriano Costigliola' \\ Marianna Maffei ${ }^{2}$ \\ Vittorio Simeon ${ }^{3}$ \\ Francesco Perna ${ }^{4}$ \\ Eugenio Tremante ${ }^{2}$ \\ Elena Merola ${ }^{5}$ \\ Carlo Antonio Leone ${ }^{2}$ \\ Andrea Bianco' \\ 'Department of Cardio-Thoracic \\ and Respiratory Sciences, Monaldi \\ Hospital, University of Campania \\ “Luigi Vanvitelli”, Naples, Italy; \\ ${ }^{2}$ Ear Nose and Throat Unit and \\ Neck Surgery, Monaldi Hospital, \\ Naples, Italy; ${ }^{3}$ Medical Statistics \\ Unit, University of Campania \\ “Luigi Vanvitelli”, Naples, Italy; \\ ${ }^{4}$ Department of Clinical Medicine \\ and Surgery, Monaldi Hospital, \\ University “Federico II”, Naples, Italy; \\ ${ }^{5}$ Bronchoscopic Unit, Public Hospital, \\ Eboli, Italy
}

\begin{abstract}
Background: A high percentage of patients with COPD report chronic nasal symptoms. The study aims to evaluate the clinical impact of a 2-month treatment with inhaled nasal budesonide (100 $\mu \mathrm{g}$ per nostril twice daily) in patients affected by COPD with chronic rhinitis comorbidity.
\end{abstract}

Patients and methods: Fifty-three stable COPD patients in therapy according to the Global initiative for chronic Obstructive Lung Disease recommendations were enrolled; 49 completed the study. At enrollment (visit 0), patients underwent skin prick test and rhinoscopy. At visit 0 and after 1 month (visit 1) and 2 months (visit 2) of therapy with nasal budesonide, patients underwent spirometry, and COPD assessment test (CAT), Sinonasal Outcome Test (SNOT 22), and modified Medical Research Council dyspnea scale were administered. Differences in continuous variables, after 2 months of treatment with nasal budesonide, were evaluated using a paired $t$-test or Wilcoxon matched-pairs signed-ranks test.

Results: Two months of treatment with nasal budesonide showed a significant statistical improvement in the total scores of CAT, SNOT 22, and modified Medical Research Council $(p<0.001)$. A significant relationship between CAT and SNOT 22 total scores at baseline and after treatment was observed.

Conclusion: The results of the present study indicate the importance of careful evaluation of the presence of chronic nasal symptoms in all COPD patients and suggest beneficial clinical effect from treatment with nasal budesonide in terms of COPD symptoms and quality of life.

Keywords: COPD, rhinitis, CAT, SNOT 22, mMRC, budesonide

\section{Introduction}

The anatomic and functional continuity of upper and lower airways is responsible for the frequent coexistence of sinonasal and lung diseases, primarily rhinitis and bronchial asthma. ${ }^{1}$ While the association between COPD and systemic extrapulmonary effects is well recognized, ${ }^{2-5}$ the link between rhinitis and COPD is still unclear, although several studies suggest an association. ${ }^{6}$

Experimental studies have demonstrated that cigarette smoke, the main risk factor for COPD, can damage nasal epithelial cells and reduce mucociliary clearance. ${ }^{6-8}$ In smokers, the inflammatory processes in both nasal and bronchial biopsies are similar, characterized by an infiltration of CD8-positive T lymphocytes associated with an increased number of neutrophils in patients with COPD or eosinophils in those with chronic bronchitis. ${ }^{9}$

Epidemiological studies have shown an association between cigarette smoking and chronic rhinitis. ${ }^{10,11}$ Furthermore, Montnemery et al ${ }^{12}$ observed that combined nasal symptoms and chronic bronchitis/emphysema were more common among smokers than nonsmokers, and Nihlén et $\mathrm{al}^{13}$ observed that symptoms such as nasal discharge
Correspondence: Cecilia Calabrese Department of Cardio-Thoracic and Respiratory Sciences, Monaldi Hospital, University of Campania “Luigi Vanvitelli”, via Leonardo Bianchi, 80I3I Naples, Italy Email cecilia.calabrese@unicampania.it (c) (i) (c) 2018 Calabrese et al. This work is published and licensed by Dove Medical Press Limited. The full terms of this license are available at https://www.dovepress.com/terms.php cc. hereby accept the Terms. Non-commercial uses of the work are permitted without any further permission from Dove Medical Press Limited, provided the work is properly attributed. For permission for commercial use of this work, please see paragraphs 4.2 and 5 of our Terms (https://www.dovepress.com/terms.php). 
and blockage predicted the incidence of chronic bronchitis/ emphysema.

Clinical studies have demonstrated that a high percentage of patients with COPD, ranging from $42 \%$ to $88 \%$, report chronic nasal symptoms. ${ }^{14-16}$ Hens et a ${ }^{17}$ and Piotrowska et $\mathrm{al}^{18}$ assessed nasal symptoms through validated questionnaires such as Sinonasal Outcome Test (SNOT 22) and an 11-point Sino-Nasal Assessment Questionnaire and recorded higher nasal endoscopic signs of inflammation in COPD patients compared with the control group. Finally, Klemence et al observed that the diagnosis of rhinosinusitis was more frequent in COPD patients when paranasal sinus computed tomography criteria were used instead of clinical criteria. ${ }^{19}$

Chronic nasal symptoms impair the quality of life and the degree of dyspnea in patients with COPD, assessed through the validated questionnaires St George's Respiratory questionnaire (SGRQ) and modified Medical Research Council (mMRC) dyspnea scale. ${ }^{15,19}$ However, studies investigating the effect of treatment of chronic rhinitis symptoms on COPD quality of life have never been performed.

Topical nasal corticosteroids are recommended by the current guidelines in patients affected by both allergic and non-allergic rhinitis in the presence of moderate/severe persistent symptoms. ${ }^{20,21}$ The aim of the study was to evaluate the impact of 2 months of rhinitis treatment with nasal budesonide on COPD quality of life, measured through COPD assessment test (CAT).

\section{Patients and methods Study population}

This was an observational study evaluating the impact of 2 months of treatment with inhaled nasal budesonide (100 $\mu \mathrm{g}$ per nostril twice daily) on the quality of life of COPD patients with persistent rhinitis, already on therapy for COPD in accordance with the Global initiative for chronic Obstructive Lung Disease (GOLD) recommendations. ${ }^{22}$

The primary end point of the study was variation of CAT score from the baseline; the secondary end points were the variations of dyspnea, evaluated by the mMRC dyspnea scale, sinonasal symptoms, evaluated through the questionnaire SNOT 22, and airway obstruction as indicated by the spirometric parameters forced expiratory volume 1 second $\left(\mathrm{FEV}_{1}\right)$, forced vital capacity $(\mathrm{FVC})$, and $\mathrm{FEV}_{1} / \mathrm{FVC}$ from the baseline.

Patients were consecutively enrolled between January 2016 and December 2016 at the Outpatient Unit of the Department of Cardio-Thoracic and Respiratory
Sciences, University of Campania “L. Vanvitelli”, Monaldi Hospital, Naples.

The diagnosis of COPD and disease classification were determined in accordance with the GOLD recommendations. $^{22}$

The diagnosis of persistent rhinitis was made in the presence of nasal symptoms (sneezing, nasal discharge, nasal obstruction, post-nasal drip, dense nasal secretions) for $>8$ weeks.

The inclusion criteria were as follows: age $\geq 45$ years, smokers or ex-smokers of at least 20 pack-years, $\mathrm{FEV}_{1} / \mathrm{FVC}<70 \%$ after four puffs of salbutamol $100 \mu \mathrm{g}$, and therapy for COPD according to the GOLD guidelines for at least 3 months.

The exclusion criteria were as follows: recent respiratory infections, common cold, or COPD exacerbations in the last 4 weeks; other concomitant lung diseases (bronchial asthma, cancer, tuberculosis, diffuse interstitial lung diseases) or severe cardiac diseases; and therapy with anti-histamine anti- $\mathrm{H}_{1}$, systemic or nasal corticosteroids, nasal decongestants, or long-term oxygen therapy.

Patients underwent three visits: at enrollment (visit 0), and after 1 month (visit 1) and 2 months (visit 2) of therapy with nasal budesonide $100 \mu \mathrm{g}$ in each nostril twice daily. At visit 0 and visit 1, patients received budesonide nasal spray (Aircort ${ }^{\circledR} 100 \mu \mathrm{g}$, kindly supplied for the study by the company ITALCHIMICI SpA, Pomezia (RM), Italy).

At visit 0 , full medical history was recorded and medical examination carried out. In particular, cigarette smoking status, the number of COPD exacerbations in the previous 2 years (defined in accordance with the GOLD recommendations), and comorbidities such as heart disease, diabetes, and obstructive sleep apnea, in addition to ongoing treatments for COPD were recorded.

All patients underwent skin prick tests with a standard series of inhaled allergens; patients with positive or negative skin prick test were defined "allergic" or "non-allergic" subjects, respectively.

Rhinolaryngoscopy was performed using a fiberscope with an external diameter of $4 \mathrm{~mm}$ (Olympus) in order to evaluate the presence of turbinate hypertrophy, nasal polyps, nasal discharge, and nasal hyperemia. Patients with purulent nasal discharge received antibiotic therapy and their enrollment was delayed to 1 month after the end of therapy.

At visits 0 , 1, and 2, patients underwent spirometry (model "Quark PTF”, COSMED) before and after salbutamol $400 \mu \mathrm{g}$, according to the guidelines of the American Thoracic Society. ${ }^{23} \mathrm{FEV}_{1}$, FVC, and $\mathrm{FEV}_{1} / \mathrm{FVC}$ were measured and the best of three forced maneuvers was recorded. 
Results were expressed both as absolute values and as a percentage of the predicted reference values of the European Respiratory Society $1993 .^{24}$

\section{Questionnaires}

At visits 0,1 , and 2 the following questionnaires were administered.

CAT is a scientifically validated questionnaire aimed at assessing the impact of COPD on the patient's health status. It consists of eight questions and each answer receives a score ranging from 0 (no impact) to 5 (the worst possible impact), with the maximum total score available being 40 . Scores from 0 to 10,11 to 20,21 to 30 , and 31 to 40 define a low, medium, high, and very high impact on patient's health status, respectively. The minimum clinically important difference in CAT score is 2 points. ${ }^{25-28}$

SNOT 22 questionnaire rates 22 different symptoms from 0 (no problem) to 5 (problem as bad as it can be) related to six domains: rhinological, ear, facial, general, physical, and psychological domains. The total score relative to the rhinological, ear, and facial subdomains was also evaluated because the comparison of the scores of each subdomain can improve the precision of the questionnaire. ${ }^{29,30}$

The mMRC dyspnea scale is a simple grading system that assesses the degree of disability caused by dyspnea in specific daily activities. It ranges from 0 to 4 and is well correlated with the quality of life and prognosis of patients with COPD. ${ }^{31-33}$

\section{Statistical analysis}

Sample size was calculated considering difference in CAT score as the primary outcome. A sample size of 52 patients achieves $81 \%$ power to detect a mean of paired differences of 0.4 in terms of effect size using a two-sided paired $t$-test with a significance level of 5\%. Continuous variables were represented as mean and SD or median and interquartile range if data were non-normally distributed, whereas categorical variables were represented as number and percentage. Differences in continuous variables, after 2 months of treatment with nasal budesonide, were evaluated using a paired $t$-test or Wilcoxon matched-pairs signed-ranks test as indicated. The role of categorical variables, such as smoking status, allergy, and exacerbations, on the questionnaires' score changes was evaluated, after controlling for baseline value, using an analysis of covariance. The score of each single item of CAT and SNOT 22 questionnaire was categorized, for further analysis, in two different ways: $1)$ as $\geq 1$ indicating all patients who answered at least one and had symptoms and 2) as $\geq 4$ indicating all patients who answered at least four and had severe symptoms. McNemar's test (pre-post on paired dichotomous variables) was used to assess the effect of treatment on each categorized item. Spearman's rank correlation test was used to determine the relationships between CAT and SNOT 22 score before and after 2 months of treatment. All tests were two-tailed, and a $p$-value $<0.05$ was considered statistically significant. Data were analyzed using $\mathrm{R}$ software 3.3.1 ( $\mathrm{R}$ foundation for Statistical Computing, Vienna, Austria).

\section{Ethics approval and consent to participate}

The study was approved by the institutional review board of Seconda Università degli studi di Napoli-Azienda Ospedaliera Universitaria S.U.N. - A.O.R.N. "Ospedali dei Colli".

\section{Results}

During the study, 53 patients were enrolled and 4 discontinued the study for personal reasons. The baseline characteristics of the 49 patients who completed the study are shown in Table 1. None of the COPD patients showed FEV reversibility criteria after treatment with $400 \mu \mathrm{g}$ salbutamol. No patient experienced exacerbations within 8 weeks before enrollment, and no modification of COPD therapy was made within the study period. Among the allergic COPD patients, one was allergic to only pollens while the others were sensitized to either dust mites (five patients) or dust mites and pollens (four patients).

Two months of treatment with nasal budesonide showed a significant statistical improvement in the total score of all the questionnaires in the study: CAT, SNOT 22, and mMRC.

Most of the patients ( $82 \%)$ reached the minimum clinically important difference in CAT score, that is, 2 points. Also, $59 \%$ of 22 patients with a medium impact on the health status (CAT score 11-20) achieved a low impact (CAT score $0-10$ ) and $60 \%$ of 15 patients with a high impact (CAT score 11-20) achieved a medium impact. Among the items of the SNOT 22 questionnaire, those related to the rhinological, ear, and facial subdomains were the most frequently impaired in patients with COPD and their total score significantly improved after nasal budesonide treatment $(p<0.001)$. However, the treatment did not significantly change the pre-bronchodilator spirometric parameters $\mathrm{FEV}_{1}$, FVC, and $\mathrm{FEV}_{1} / \mathrm{FVC}$ (Table 2).

When the study population was divided into subgroups according to baseline criteria, smoking status, history of 
Table I Baseline characteristics

\begin{tabular}{|c|c|}
\hline Variables & \\
\hline Age, mean $\pm S D$ & $64.7 \pm 9.4$ \\
\hline Male, n (\%) & $35(71.4)$ \\
\hline \multicolumn{2}{|l|}{ Smokers } \\
\hline Current, n (\%) & $27(55.1)$ \\
\hline Former, n (\%) & $22(44.9)$ \\
\hline \multicolumn{2}{|l|}{ Exacerbations $\geq 2 /$ previous year } \\
\hline Yes, n (\%) & $33(67.4)$ \\
\hline No, n (\%) & $16(32.6)$ \\
\hline \multicolumn{2}{|l|}{ Comorbidity } \\
\hline Cardiovascular diseases, n (\%) & $17(34.7)$ \\
\hline Diabetes, n (\%) & $3(6.1)$ \\
\hline OSAS, n (\%) & $3(6.1)$ \\
\hline \multicolumn{2}{|l|}{ GOLD spirometry grade, $\mathrm{n}(\%)$} \\
\hline I. Mild & $5(10.2)$ \\
\hline 2. Moderate & $30(6 \mid .2)$ \\
\hline 3. Severe & $12(24.5)$ \\
\hline 4. Very severe & $2(4.1)$ \\
\hline \multicolumn{2}{|l|}{ GOLD groups, n (\%) } \\
\hline$A$ & $3(6)$ \\
\hline B & I I (22.5) \\
\hline C & $10(20.5)$ \\
\hline $\mathrm{D}$ & $25(5 \mathrm{I})$ \\
\hline \multicolumn{2}{|l|}{ COPD therapy, n (\%) } \\
\hline LAMA & $12(24.5)$ \\
\hline LABA/ICS & $4(8)$ \\
\hline LAMA/LABA & $9(18.5)$ \\
\hline LAMA/LABA/ICS & $24(49)$ \\
\hline \multicolumn{2}{|l|}{ Allergy, n (\%) } \\
\hline Yes & II (22.5) \\
\hline No & $38(77.5)$ \\
\hline \multicolumn{2}{|l|}{ Nasal endoscopy, n (\%) } \\
\hline Turbinates hypertrophy & $13(26.5)$ \\
\hline Nasal discharge & $32(65.3)$ \\
\hline Nasal hyperemia & $20(40.8)$ \\
\hline
\end{tabular}

Abbreviations: GOLD, Global initiative for chronic Obstructive Lung Disease; ICS, inhaled corticosteroid; LABA, long-acting beta 2 agonists; LAMA, long-acting muscarinic antagonists; OSAS, obstructive sleep apnea.

Table 2 CAT, SNOT 22, mMRC score, and spirometric variables at baseline and at the end of the study

\begin{tabular}{|c|c|c|c|}
\hline Variables & $\begin{array}{l}\text { Pre-nasal } \\
\text { budesonide }\end{array}$ & $\begin{array}{l}\text { Post-nasal } \\
\text { budesonide }\end{array}$ & $p$-value \\
\hline CAT total score & I5 (II-2I) & $8(5-12)$ & $<0.001$ \\
\hline SNOT 22 total score & $24(15-32)$ & $10(7-15)$ & $<0.001$ \\
\hline SNOT rhino/ear-facial score & $19(11-25)$ & $9(6-12)$ & $<0.001$ \\
\hline mMRC total score & $2(I-2)$ & I (0-2) & $<0.001$ \\
\hline \multicolumn{4}{|l|}{ Spirometry } \\
\hline $\mathrm{FEV}_{1}(\mathrm{~L})$ pre-bd & $1.49(1.05-2.1)$ & $1.4 \mathrm{I}(\mathrm{I} . \mathrm{I}-2 . \mathrm{I})$ & 0.78 \\
\hline $\mathrm{FEV}_{1}(\%)$ pre-bd & $58(5 I-72)$ & $61(52-74)$ & 0.22 \\
\hline FVC (L) pre-bd & $2.69(1.9-3.6)$ & $2.68(2.2-3.4)$ & 0.39 \\
\hline FVC (\%) pre-bd & $86(72-95)$ & $87(74-97)$ & 0.13 \\
\hline $\mathrm{FEV}_{\mathrm{I}} / \mathrm{FVC}(\%)$, mean (SD) & $58.6(1.2)$ & $57.7(1.1)$ & 0.42 \\
\hline
\end{tabular}

Notes: Data distribution is described as median and IQR, except when specified. Wilcoxon matched-pairs signed-ranks test was used. Paired $t$-test was used for FEV /FVC \% differences.

Abbreviations: CAT, COPD assessment test; $\mathrm{FEV}_{1}$, forced expiratory volume in I second; FVC, forced vital capacity; IQR, interquartile range; mMRC, modified Medical Research Council; pre-bd, pre-bronchodilator; SNOT 22, Sinonasal Outcome Test. exacerbations, allergy, GOLD groups ( $\mathrm{A}+\mathrm{B}$ vs $\mathrm{C}+\mathrm{D})$, GOLD spirometry grades $(1+2$ vs $3+4)$, and inhaled corticosteroid (ICS) therapy (ICS/long-acting beta 2 agonists [LABA] or ICS/LABA/long-acting muscarinic antagonists [LAMA] vs ICS-free therapy [LABA/LAMA or LAMA]), nasal budesonide treatment showed a consistent efficacy pattern across the subgroups. The score improvement for each questionnaire, after controlling for score at enrollment, was independent of these baseline criteria and there was no statistical difference among the subgroups (Figure 1).

According to the answers given to the CAT questions, the symptoms more frequently reported (score $\geq 1$ ) and more disabling (score $\geq 4$ ) for patients with COPD were breathlessness when walking (question 4), followed by cough, mucus in the chest, and limitation performing activities (question 1 , 2 , and 5 , respectively). All these symptoms significantly improved following the addition of nasal budesonide to the ongoing treatment of COPD (Table 3).

All nasal symptoms (questions $1-8$ of SNOT 22) improved after nasal budesonide treatment in terms of frequency or intensity. Post-nasal discharge was the symptom more frequently reported (score $\geq 1$ ) and disabling (score $\geq 4$ ) for COPD patients (Table 4).

A significant relationship was observed between CAT total score and SNOT 22 total score at baseline and between the changes in both questionnaires' scores due to the addition of inhaled nasal budesonide to the ongoing treatment for COPD. No significant relationship was observed between SNOT 22 total score and $\mathrm{FEV}_{1}$ at baseline and between the changes of SNOT 22 total score and $\mathrm{FEV}_{1}$ after nasal therapy (Figure 2).

\section{Discussion}

The results of the present study demonstrate, for the first time, the effectiveness of add-on treatment with nasal budesonide in improving the health status of patients affected by COPD and persistent rhinitis already on therapy according to the GOLD recommendations.

In addition to the impact on CAT score, 8 weeks of therapy with nasal budesonide improved the degree of dyspnea and symptoms of rhinitis, assessed through the mMRC dyspnea scale and the SNOTT 22 questionnaire, respectively. On the contrary, nasal budesonide did not change airway function impairment.

Despite progress in COPD therapy, ${ }^{34}$ recent studies demonstrate that a significant proportion of patients remain symptomatic and the presence of symptoms in any part of the day is associated with a worst quality of life, measured 


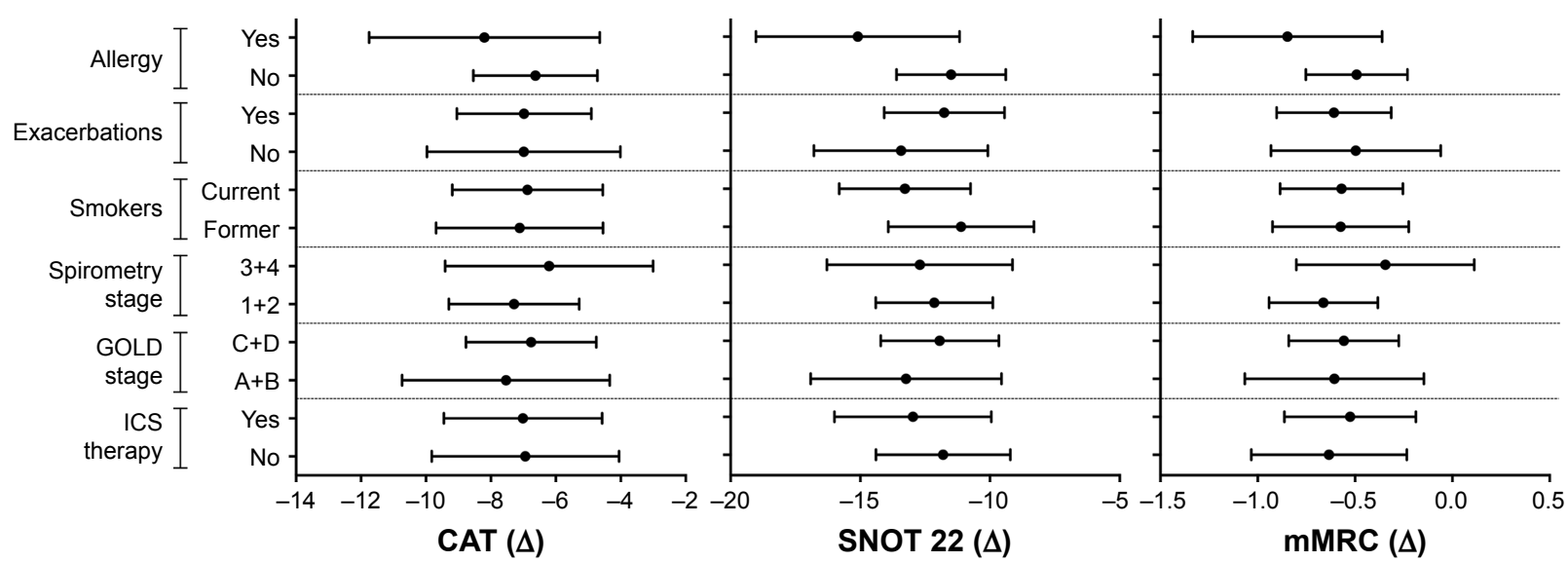

Figure I Graphs represent differences, controlled by score at enrollment, in CAT, SNOT 22, and mMRC questionnaires among subgroups according to allergy, history of exacerbations, smoking status, spirometry stage, GOLD stage, and ICS therapy.

Note: Each point represents mean difference with the bar at $95 \% \mathrm{Cl}$.

Abbreviations: CAT, COPD assessment test; GOLD, Global initiative for chronic Obstructive Lung Disease; ICS, inhaled corticosteroid; mMRC, modified Medical Research Council; SNOT 22, Sinonasal Outcome Test.

through the CAT questionnaire. ${ }^{35,36}$ In accordance with our data, Miravitlles et al observed that dyspnea, evaluated by the mMRC scale, is the most frequent symptom being reported by $>70 \%$ of COPD patients, followed by coughing and bringing up phlegm or mucus; symptomatic COPD patients have worse anxiety and depression levels and sleep quality compared with patients without symptoms. ${ }^{36}$ For this reason, the results of this study, showing an improvement of COPD symptoms and quality of life following the treatment of rhinitis comorbidity, takes on a particular clinical relevance. Although $>50 \%$ of our COPD patients were on treatment with ICS added to either LABA and LABA/LAMA for at least 6 months, they exhibited chronic nasal symptoms, allowing us to exclude a crossover effect of ICS on nasal symptoms. It is very important to highlight that none of the COPD patients enrolled in the study were aware of their nasal symptoms and they had never performed either a nose, ear, and throat visit with rhinoscopy or skin prick tests. Upper airway symptoms are often undervalued by COPD patients and are therefore undertreated. In the present study, use of the validated screening questionnaire for rhinitis, SNOT 22, may have increased the detection of the comorbidity, as has been shown in patients with difficult asthma. ${ }^{37}$ In addition, Hurst et al demonstrated that upper airway involvement in COPD patients could be detected through quality of life tools specific for the assessment of rhinosinusitis, such as SNOT 20, but not by questionnaires such as SGRQ focused on lower respiratory tract symptoms. ${ }^{16}$ However, Caillaud et al observed that rhinitis comorbidity severely impacts the quality of life of COPD patients, showing an independent association between chronic nasal symptoms and the activity score at the SGRQ. ${ }^{14}$ In the present study, the health status of COPD patients was evaluated through CAT that, in comparison with the SGRQ, is more practical to use and shares similar psychometric

Table 3 Percentage of score $\geq I$ and $\geq 4$ for each item of CAT

\begin{tabular}{|c|c|c|c|c|c|c|}
\hline \multirow{2}{*}{$\begin{array}{l}\text { CAT } \\
\text { Questions (n) }\end{array}$} & \multicolumn{3}{|l|}{$\%$ score $\geq I$} & \multicolumn{3}{|l|}{$\%$ score $\geq 4$} \\
\hline & $\begin{array}{l}\text { Pre-nasal } \\
\text { budesonide, \% }\end{array}$ & $\begin{array}{l}\text { Post-nasal } \\
\text { budesonide, \% }\end{array}$ & $p$-value & $\begin{array}{l}\text { Pre-nasal } \\
\text { budesonide, \% }\end{array}$ & $\begin{array}{l}\text { Post-nasal } \\
\text { budesonide, \% }\end{array}$ & $p$-value \\
\hline I. Cough & 86 & 61 & 0.004 & 41 & 14 & 0.001 \\
\hline 2. Mucus in the chest & 80 & 57 & 0.003 & 37 & 6 & 0.0003 \\
\hline 3. Chest tightness & 55 & 39 & 0.04 & 16 & 4 & 0.07 \\
\hline 4. Breathless when walking & 98 & 86 & 0.07 & 45 & 14 & 0.003 \\
\hline 5. Limited doing activities & 76 & 61 & 0.065 & 27 & 10 & 0.02 \\
\hline 6. Confident living home & 55 & 20 & $0.00 \mathrm{I}$ & 8 & 2 & 0.38 \\
\hline 7. Do not sleep soundly & 51 & 24 & 0.004 & 12 & 4 & 0.22 \\
\hline 8. No energy & 67 & 65 & $>0.99$ & 10 & 6 & 0.69 \\
\hline
\end{tabular}

Note: $p$-value are calculated using McNemar's test.

Abbreviation: CAT, COPD assessment test. 
Table 4 Percentage of score $\geq I$ and $\geq 4$ for each item of SNOT 22 nose, ear, and facial subdomains

\begin{tabular}{|c|c|c|c|c|c|c|}
\hline \multirow{2}{*}{$\frac{\text { SNOT } 22}{\text { Questions (n) }}$} & \multicolumn{3}{|l|}{$\%$ score $\geq \mathbf{I}$} & \multicolumn{3}{|l|}{$\%$ score $\geq 4$} \\
\hline & $\begin{array}{l}\text { Pre-nasal } \\
\text { budesonide, \% }\end{array}$ & $\begin{array}{l}\text { Post-nasal } \\
\text { budesonide, \% }\end{array}$ & $p$-value & $\begin{array}{l}\text { Pre-nasal } \\
\text { budesonide, \% }\end{array}$ & $\begin{array}{l}\text { Post-nasal } \\
\text { budesonide, \% }\end{array}$ & $p$-value \\
\hline I. Need to blow nose & 71 & 55 & 0.08 & 31 & 6 & 0.004 \\
\hline 2. Sneezing & 76 & 51 & 0.002 & 12 & 4 & 0.13 \\
\hline 3. Runny nose & 61 & 31 & 0.002 & 16 & 0 & 0.008 \\
\hline 4. Nasal obstruction & 73 & 45 & 0.003 & 27 & 6 & 0.006 \\
\hline 5. Loss of smell or taste & 43 & 31 & 0.18 & 18 & 4 & 0.04 \\
\hline 6. Cough & 80 & 57 & 0.02 & 29 & 10 & 0.035 \\
\hline 7. Post-nasal discharge & 84 & 55 & 0.003 & 31 & 2 & 0.0001 \\
\hline 8. Thick nasal discharge & 61 & 41 & 0.05 & 14 & 0 & 0.016 \\
\hline 9. Ear fullness & 43 & 43 & $>0.99$ & 12 & 4 & 0.22 \\
\hline 10. Dizziness & 43 & 31 & 0.21 & 8 & 2 & 0.38 \\
\hline II. Ear pain & 14 & 12 & $>0.99$ & 0 & 0 & $>0.99$ \\
\hline 12. Facial pain/pressure & 43 & 31 & 0.18 & 18 & 0 & 0.004 \\
\hline
\end{tabular}

Note: $p$-values are calculated using McNemar's test.

Abbreviation: SNOT 22, Sinonasal Outcome Test.

properties. ${ }^{25} \mathrm{CAT}$ has been shown to be sensitive enough to evaluate changes in health status associated with treatments for COPD. ${ }^{26}$ The involvement of upper airways in COPD patients has been investigated by several authors, and overall, these studies have shown that a high percentage of patients with COPD have symptoms consistent with persistent rhinitis. ${ }^{6}$ Our results, demonstrating a significant association between
SNOT 22 and CAT scores, both at baseline and after 2 months of treatment with inhaled budesonide, highlight the interaction between the upper and lower airways in COPD.

Whether a correlation between nasal symptoms and $\mathrm{FEV}_{1}$ does exist still remains controversial. Indeed, Roberts et al did not find any relationship between nasal symptoms and $\mathrm{FEV}_{1}$ values, ${ }^{15}$ while Hurst et al demonstrated a correlation
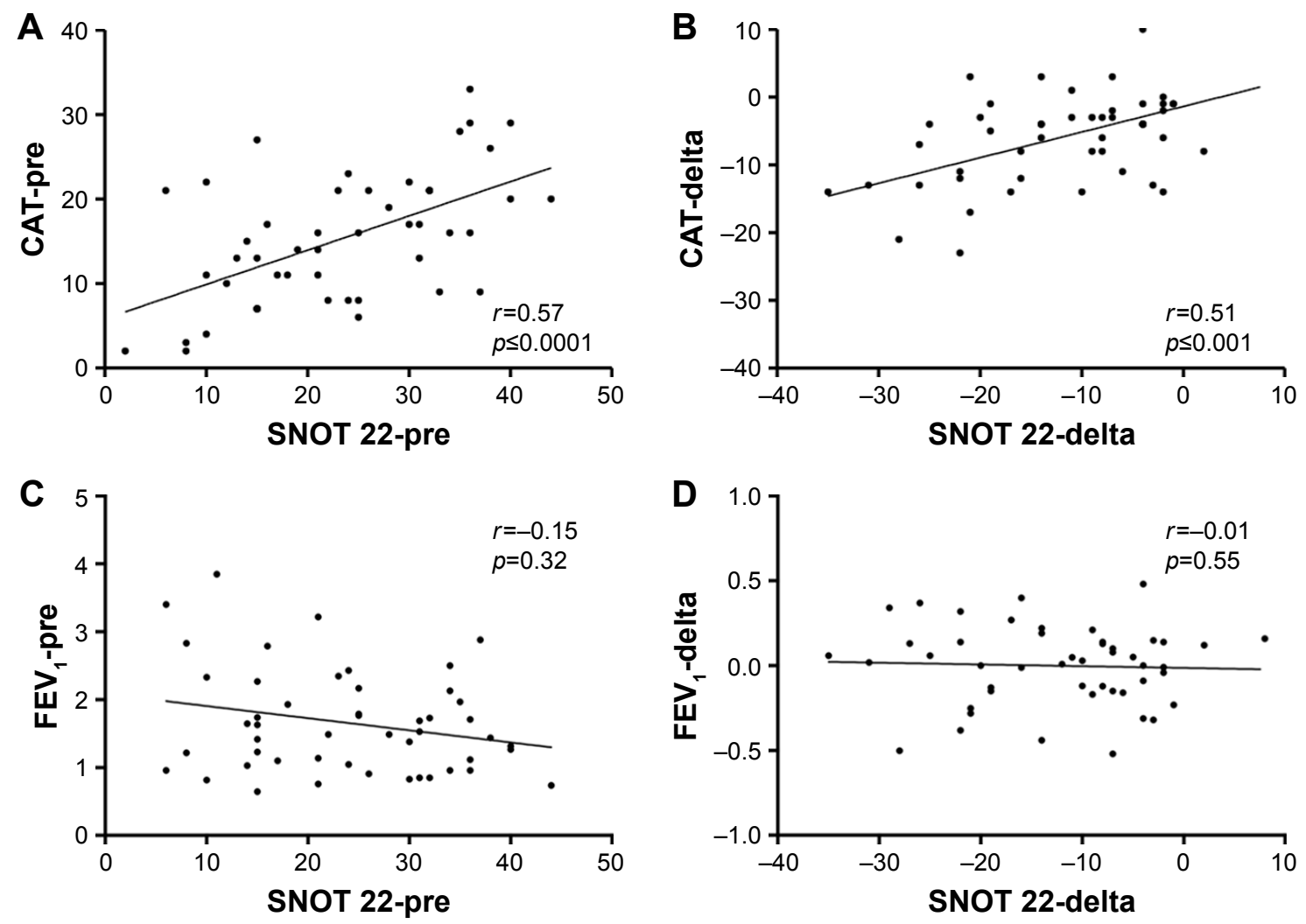

Figure 2 Scatter plots representing FEV, values, CAT, and SNOT 22 questionnaire scores at enrollment (visit 0) and after therapy (delta, difference between visit 2 and visit 0). Spearman's rank correlation test was used to determine the relationships between axis.

Note: CAT and SNOT 22 correlation (A, B); FEV, and SNOT 22 correlation (C, D).

Abbreviations: CAT, COPD assessment test; FEV ${ }_{1}$, forced expiratory volume in I second; SNOT 22, Sinonasal Outcome Test. 
between the degree of nasal airway obstruction, measured by acoustic rhinometry, and the impairment to pulmonary airflow, measured by spirometry. ${ }^{38}$ In this study, we did not find either an association between $\mathrm{FEV}_{1}$ and SNOT 22 symptoms score at baseline or an improvement of the airway function impairment after the administration of nasal budesonide, although to achieve definitive results, long-term studies should be performed.

The mechanism by which nasal budesonide therapy can improve the symptoms of COPD is unknown. In patients with bronchial asthma, a recent meta-analysis showed that treatment of allergic rhinitis with nasal steroids significantly improves functional and clinical asthma outcomes. ${ }^{39}$ Nasal steroids have been shown to be effective not only in allergic rhinitis but also in inflammatory and non-inflammatory cell phenotypes of non-allergic rhinitis, although to a lower degree. ${ }^{40}$ Cellular characteristics of rhinitis in COPD have not been extensively investigated. It is conceivable that in COPD patients, treatment of coexistent rhinitis with nasal steroids could lead to improvement of symptoms associated with lower airways, despite steroid insensitivity shown by most of them. There is a need to understand whether nasal steroids are able to restore air conditioning functions of the nose, alleviate upper/lower airway reflex, and reduce the aspiration of nasal secretions as well as reabsorption of inflammatory mediators in rhinitis associated with COPD. In comparison with other nasal steroids, such as fluticasone, a recent study demonstrated that budesonide, an ICS with potent anti-inflammatory activity, ${ }^{41}$ forming esters in the human nasal mucosa, is retained in the nasal mucosa to a greater extent. ${ }^{42}$

Although the present study has several limitations including the lack of a placebo-controlled study arm, our findings demonstrated the real-life impact of treatment of rhinitis in COPD patients for the first time. A longer placebo-controlled study is required to clearly define the relevance of the nasal inflammatory process in COPD patients and the effects of nasal corticosteroid treatment on other important clinical end points such as frequency of exacerbations of COPD.

\section{Conclusion}

The results of the present study support the importance of careful evaluation of the presence of chronic nasal symptoms in all COPD patients, considering the beneficial effect of treatment with nasal budesonide on COPD symptoms and quality of life.

\section{Data sharing statement}

The data that support the findings of this study are available from the authors upon request.

\section{Acknowledgment}

The authors wish to thank Prof Paolo Chiodini for his assistance with data analysis.

\section{Author contributions}

All authors contributed toward data analysis, drafting and revising the paper and agree to be accountable for all aspects of the work. VS was the study statistician.

\section{Disclosure}

The authors report no conflicts of interest in this work.

\section{References}

1. Feng CH, Miller MD, Simon RA. The united allergic airway: connections between allergic rhinitis, asthma, and chronic sinusitis. Am J Rhinol Allergy. 2012;26(3):187-190.

2. Clini EM, Beghé B, Fabbri LM. Chronic obstructive pulmonary disease is just one component of the complex multimorbidities in patients with COPD. Am J Respir Crit Care Med. 2013;187(7):668-671.

3. de Blasio F, de Blasio F, Miracco Berlingieri G, et al. Evaluation of body composition in COPD patients using multifrequency bioelectrical impedance analysis. Int J Chron Obstruct Pulmon Dis. 2016;11: 2419-2426.

4. Bianco A, Nigro E, Monaco ML, et al. The burden of obesity in asthma and COPD: role of adiponectin. Pulm Pharmacol Ther. 2017;43:20-25.

5. Testa G, Cacciatore F, Bianco A, et al. Chronic obstructive pulmonary disease and long-term mortality in elderly subjects with chronic heart failure. Aging Clin Exp Res. 2017;29(6):1157-1164.

6. Håkansson K, Konge L, Thomsen SF, Backer V, von Buchwald C. Sinonasal inflammation in COPD: a systematic review. Eur Respir J. 2013;42(5):1402-1411.

7. Reh DD, Higgins TS, Smith TL. Impact of tobacco smoke on chronic rhinosinusitis: a review of the literature. Int Forum Allergy Rhinol. 2012;2(5):362-369.

8. Tamashiro E, Xiong G, Anselmo-Lima WT, Kreindler JL, Palmer JN, Cohen NA. Cigarette smoke exposure impairs respiratory epithelial ciliogenesis. Am J Rhinol Allergy. 2009;23(2):117-122.

9. Vachier I, Vignola AM, Chiappara G, et al. Inflammatory features of nasal mucosa in smokers with and without COPD. Thorax. 2004; 59(4):303-307.

10. Hastan D, Fokkens WJ, Bachert C, et al. Chronic rhinosinusitis in Europe-an underestimated disease. A GA²LEN study. Allergy. 2011; 66(9):1216-1223.

11. Eriksson J, Ekerljung L, Sundblad BM, et al. Cigarette smoking is associated with high prevalence of chronic rhinitis and low prevalence of allergic rhinitis in men. Allergy. 2013;68(3):347-354.

12. Montnemery P, Svensson C, Adelroth E, et al. Prevalence of nasal symptoms and their relation to self-reported asthma and chronic bronchitis/ emphysema. Eur Respir J. 2001;17(4):596-603.

13. Nihlén U, Montnémery P, Andersson M, et al. Specific nasal symptoms and symptom-provoking factors may predict increased risk of developing COPD. Clin Physiol Funct Imaging. 2008;28(4):240-250.

14. Caillaud D, Chanez P, Escamilla R, et al; Initiatives BPCO Scientific Committee and Investigators. Association of chronic nasal symptoms with dyspnoea and quality-of-life impairment in chronic obstructive pulmonary disease. Respirology. 2014;19(3):346-352.

15. Roberts NJ, Lloyd-Owen SJ, Rapado F, et al. Relationship between chronic nasal and respiratory symptoms in patients with COPD. Respir Med. 2003;97(8):909-914.

16. Hurst JR, Wilkinson TM, Donaldson GC, Wedzicha JA. Upper airway symptoms and quality of life in chronic obstructive pulmonary disease (COPD). Respir Med. 2004;98(8):767-770. 
17. Hens G, Vanaudenaerde BM, Bullens DM, et al. Sinonasal pathology in nonallergic asthma and COPD: "united airway disease" beyond the scope of allergy. Allergy. 2008;63(3):261-267.

18. Piotrowska VM, Piotrowski WJ, Kurmanowska Z, Marczak J, Górski P, Antczak A. Rhinosinusitis in COPD: symptoms, mucosal changes, nasal lavage cells and eicosanoids. Int J Chron Obstruct Pulmon Dis. 2010;5:107-117.

19. Klemence A, Abadoglu O, Gumus C, Berk S, Epozturk K, Akkurt I. The frequency of chronic rhinosinusitis/nasal polyp in COPD and its effect on the severity of COPD. COPD. 2011;8(1):8-12.

20. Angier E, Willington J, Scadding G, Holmes S, Walker S; British Society for Allergy \& Clinical Immunology (BSACI) Standards of Care Committee. Management of allergic and non-allergic rhinitis: a primary care summary of the BSACI guideline. Prim Care Respir J. 2010;19(3):217-222.

21. Scadding GK, Durham SR, Mirakian R, et al; British Society for Allergy and Clinical Immunology. BSACI guidelines for the management of allergic and non-allergic rhinitis. Clin Exp Allergy. 2008;38(1):19-42.

22. Global Initiative for Chronic Obstructive Lung Disease (GOLD). Global strategy for the diagnosis, management, and prevention of chronic obstructive pulmonary disease-2016. GOLD website. Available from: http://www.goldcopd.org

23. Standardization of spirometry, 1994 update. American thoracic society. Am J Respir Crit Care Med. 1995;152(3):1107-1136.

24. Quanjer PH, Tammeling GJ, Cotes JE, et al. Lung volumes and forced ventilator flows. Report working party standardization of lung function tests, European community for steel and coal official statement of the European respiratory society. Eur Respir J. 1993;16:5-40.

25. Jones PW, Harding G, Berry P, Wiklund I, Chen WH, Kline Leidy N. Development and first validation of the COPD assessment test. Eur Respir J. 2009;34(3):648-654.

26. Dodd JW, Hogg L, Nolan J, et al. COPD assessment test (CAT): response to pulmonary rehabilitation. A multicentre, prospective study. Thorax. 2011;66(5):425-429.

27. Kon SS, Canavan JL, Jones SE, et al. Minimum clinically important difference for the COPD Assessment Test: a prospective analysis. Lancet Respir Med. 2014;2(3)195-203.

28. Ghobadi H, Ahari SS, Kameli A, Lari SM. The relationship between COPD Assessment Test (CAT) scores and severity of airflow obstruction in stable COPD patients. Tanaffos. 2012;11(2):22-26.

29. Hopkins C, Gillet S, Slack R, Lund VJ, Browne JP. Psychometric validity of the 22-item Sinonasal outcome test. Clin Otolaryngol. 2006;31(2):103-109.
30. Pyonnonen MA, Kim HM, Terrel JE. Validation of the Sino-Nasal Outcome test 20 (SNOT 20) domains in nonsurgical patients. Am J Rhinol Allergy. 2009;23(1):40-45.

31. Chhabra SK, Gupta AK, Khuma MZ. Evaluation of three scales of dyspnea in chronic obstructive pulmonary disease. Ann Thorac Med. 2009;4(3):128-132.

32. Perez T, Burgel PR, Paillasseur JL, et al; INITIATIVES BPCO Scientific Committee. Modified medical Research Council scale vs Baseline Dyspnea Index to evaluate dyspnea in chronic obstructive pulmonary disease. Int J Chron Obstruct Pulmon Dis. 2015;10:1663-1672.

33. Camargo LA, Pereira CA. [Dyspnea in COPD: beyond the modified Medical Research Council Scale]. J Bras Pneumol. 2010;36(5): 571-578. Portuguese.

34. Pelaia G, Vatrella A, Busceti MT, et al. Pharmacologic rationale underlying the therapeutic effects of tiotropium/olodaterol in COPD. Ther Clin Risk Manag. 2015;11:1563-1572.

35. Roche N, Small M, Broomfield S, Higgins V, Pollard R. Real world COPD: association of morning symptoms with clinical and patient reported outcomes. COPD. 2013;10(6):679-686.

36. Miravitlles M, Worth $\mathrm{H}$, Soler Cataluña JJ, et al. Observational study to characterise 24-hour COPD symptoms and their relationship with patient-reported outcomes: results from the ASSESS study. Respir Res. 2014; $15: 122$.

37. Radhakrishna N, Tay TR, Hore-Lacy F, et al. Validated questionnaires heighten detection of difficult asthma comorbidities. J Asthma. 2017; 54(3):294-299

38. Hurst JR, Kuchai R, Michael P, Perera WR, Wilkinson TM, Wedzicha JA. Nasal symptoms, airway obstruction and disease severity in chronic obstructive pulmonary disease. Clin Physiol Funct Imaging. 2006;26(4): 251-256.

39. Lohia S, Schlosser RJ, Soler ZM. Impact of intranasal corticosteroids on asthma outcomes in allergic rhinitis: a meta-analysis. Allergy. 2013; 68(5):569-579

40. Kirtsreesakul V, Hararuk K, Leelapong J, Ruttanaphol S. Clinical efficacy of nasal steroids on nonallergic rhinitis and the associated inflammatory cell phenotypes. Am J Rhinol Allergy. 2015;29(5):343-349.

41. Vatrella A, Perna F, Pelaia G, et al. T cell activation state in the induced sputum of asthmatics treated with budesonide. Int J Immunopathol Pharmacol. 2010;23(3):745-753.

42. Petersen H, Kullberg A, Staffan E, Greiff L. Nasal retention of budesonide and fluticasone in man: formation of airway mucosal budesonideesters in vivo. Br J Clin Pharmacol. 2001;51(2):159-163.
International Journal of COPD

\section{Publish your work in this journal}

The International Journal of COPD is an international, peer-reviewed journal of therapeutics and pharmacology focusing on concise rapid reporting of clinical studies and reviews in COPD. Special focus is given to the pathophysiological processes underlying the disease, intervention programs, patient focused education, and self management protocols.
Dovepress

This journal is indexed on PubMed Central, MedLine and CAS. The manuscript management system is completely online and includes a very quick and fair peer-review system, which is all easy to use. Visit http://www.dovepress.com/testimonials.php to read real quotes from published authors. 